\title{
Does Preoperative Balance Training Reduce Pain and Improve Joint Function in Patients After Total Knee Arthroplasty? A Randomized Controlled Trial
}

\section{Wang Chen}

Affiliated Hospital of Xuzhou Medical University

Jian-Ning Sun

Affiliated Hospital of Xuzhou Medical University

Zheng-Hao Hu

Affiliated Hospital of Xuzhou Medical University

Xiang-Yang Chen ( $\nabla$ xzchenxiangyang@163.com )

Department of Orthopedic Surgery, Affiliated Hospital of Xuzhou Medical University, 99 Huaihai Road,

Xuzhou, Jiangsu 221002, China https://orcid.org/0000-0001-7376-6179

Shuo Feng

Affiliated Hospital of Xuzhou Medical University

Research article

Keywords: Prehabilitation, Osteoarthritis, Balance training, Total knee arthroplasty, Pain, Joint function, Randomized controlled trial

Posted Date: October 22nd, 2020

DOl: https://doi.org/10.21203/rs.3.rs-93187/v1

License: (c) (1) This work is licensed under a Creative Commons Attribution 4.0 International License. Read Full License 


\section{Abstract}

Background Part of patients undergoing TKA did not achieve the expected physiological function results. The purpose of this study was to investigate whether preoperative balance training can reduce pain and improve joint function after TKA.

Methods 100 patients with knee osteoarthritis (OA) prepared for TKA, according to the inclusion and exclusion criteria, were randomly divided into balance training group (50 patients) and control group (50 patients). The main evaluation outcomes of the study included early functional milestones, ROM, WOMAC score, keen society score (KSS), KOOS score, and complications at 1 month (baseline) and 1 day before surgery, 6 weeks (main endpoint) and 52 weeks (1 year) after surgery.

Results 4 patients lost to follow-up at 1 month before surgery, 96 received planned surgery and 86 underwent a complete postoperative evaluation. After TKA, many indicators of the two groups, including WOMAC score, KSS, KOOS score, were significantly improved compared with before surgery. At 52 weeks after TKA, no statistically significant difference between the balance training group and control group in attain early functional milestones, ROM, WOMAC score, KSS, KOOS score, and complications; however, at 6 weeks after surgery, balance training group had better early benefits in stopping all narcotics $(P=$ $0.045)$, relieving pain $(P=0.037)$, improving function $(P=0.017)$ and quality of life (QOL) $(P=0.028)$.

Conclusions Although there were no difference between preoperative balance training group and control group at the 52 weeks after surgery, however, preoperative balance training can relieve pain and improve function in the early stage ( 6 weeks), but adequately statistically powered trials are needed to confrm the accuracy of the study results

\section{Trial Registration ChiCTR2000032789.}

\section{Introduction}

Total knee arthroplasty (TKA) has been shown to change knee mechanics, relieve pain, increase knee ROM, improve knee function and physical balance for patients with knee disease. ${ }^{[1-3]}$ As the population ages and the effectiveness of surgery, the number of patients undergoing TKA due to knee OA continues to increase. ${ }^{[4]}$ TKA has greatly improved the adverse symptoms of the knee, and most patients are satisfied with the efficacy of TKA, ${ }^{[5]}$ however, about $20 \%$ of patients still suffer from chronic knee pain after surgery, and $15 \%$ of them have not found the exact pathogeny through radiographic images. ${ }^{[6,7]}$ Some patients still have limb imbalance, ${ }^{[8,9]}$ difficulties in walking and climbing stairs for a long period of months after surgery, ${ }^{[10,11]}$ as well as some patients have persistent sensorimotor dysfunction, ${ }^{[12]}$ which indicates that part of patients do not achieve the expected physiological function results after TKA.

Incomplete proprioceptive recovery of the knee, poor mobility and unstable dynamic balance are factors that increase the risk of falls in the elderly, and are also common factors that lead to difficulty in completing daily activities. ${ }^{[13,14]}$ It has been reported that $25 \%$ of patients will fall within 2 years after 
total joint arthroplasty, ${ }^{[15]}$ resulting in physical and psychological trauma and a high cost to the patient. [16] Therefore, balance is particularly important for the basic daily activities and safety of patients with TKA.

Balance training not only refers to proprioception or neuromuscular training, but also sensorimotor training. ${ }^{[17]}$ Postoperative balance training can relieving pain, increasing the knee ROM, restoring muscle strength, improving joint function, and early postoperative results. ${ }^{[14,17]}$ Domínguez and Moutzouri also supported balance training as part of postoperative rehabilitation programs, which provide good solutions for improving the adverse symptoms after TKA. ${ }^{[18,19]}$ However, conclusive evidence on the benefits of preoperative balance training is currently uncertain, so its effectiveness has not been determined. Gstoettner held that preoperative proprioception training can improve standing balance, however, Bitterli deemed that sensory motor training does not have any useful benefits for patients. ${ }^{[20,21]}$ Previously published studies have not drawn consistent evidence. The purpose of this study was to evaluate the effectiveness of TKA and focus on exploring whether preoperative balance training can reduce pain and improve joint function after TKA.

\section{Materials And Methods}

The randomized controlled study (RCT) has been approved by the local ethics committee and registered with the Chinese Clinical Trial Registry (identifier: ChiCTR2000032789). It mainly evaluates the indicators of 1 month (baseline) and 1 day before surgery, 6 weeks (main endpoint) and 52 weeks after surgery. Flow diagram of patients participating in this study is shown in Figure 1.

We have counted patients who have undergone clinical and imaging evaluation, osteoarthritis as severe, radiological degenerative change to grade $\nabla$ or $\nabla$ and have surgical plans. ${ }^{[22]}$ As a result of the significant disruption that caused by the COVID-19 pandemic, they cannot go to the hospital for surgical treatment in time. The inclusion criteria were as follows: patients with severe unilateral knee OA; patients who were preparing for primary TKA; patients with no discomfort on the contralateral knee, hip, and ankle; choose prostheses of the same manufacturer and the same material; with the informed consent of patients and their families, patients can comply with the requirements of the study, including preoperative and postoperative evaluations and questionnaire surveys, and sign informed consent. Those who meet the following conditions were excluded: severe heart, kidney and lung insufficiency, tumor; patients with rheumatism or vestibular dysfunction; neuromuscular system diseases, such as stroke, Parkinson's disease, peripheral nerve diseases, etc.; previous joint infections or severe medical illnesses have restricted walking; patient with revision of knee prosthesis. Based on inclusion and exclusion criteria, we included a total of 100 patients between January 2019 and October 2019.

The nurse prepared two opaque cartons with similar shapes and sizes, labeled "balance training group" and "control group" respectively, and patients were divided into training group and control group according to the selected carton card. Qualified participants' baseline assessment and general details were completed by specific researchers. The researcher informed sports medicine doctors about the 
allocation of eligible participants to the intervention group. Sports medicine doctors will guide the intervention group through writing and telephone to carry out balance training for 1 month. The researchers evaluate various indicators of patients who have completed balance training. The detailed patient data were not clear to anyone except the specific researcher, including the one doctor responsible for the operation. The follow-up data at 6 weeks and 52 weeks after surgery were also completed by specific researchers. This study meets the ethical standards proposed by Harris and Atkinson. ${ }^{[23]}$

All operations were performed by one experienced professional surgeon who have completed more than 100 TKA in our orthopedics department, and assisted by a professional anesthesiologist. All patients underwent surgery under general anesthesia. Supervise and guide the postoperative rehabilitation exercise of all surgical patients, the balance training group and the control group adopt the same kind of exercise method with the same procedure.

The control group took oral pain medication for a period of 1 month, while the training group took symptomatic treatment with the same kind and dose of analgesic drug, they also conducted balance training in the outpatient clinic. All patients in the balance training group received written and telephone guidance of the training, and performed balance training at home for a month or so, 45 minutes each time, every two days. One month later, they were admitted to the hospital for surgical treatment according to the epidemic situation.

Balance training were based on the Brotzman principle ${ }^{[24]}$ and the standard rehabilitation program of clinical experience, and were trained according to the actual situation of patients and families. Kicking the ball exercises: the patient takes a sitting position, both feet are on both sides of the basketball, and the basketball is rolled with the feet around and around. Imaginary pedaling exercise: the patient takes the supine position and simulate stepping on an imaginary bicycle, stops when the lower limbs are sore. Balance board practice: the patient takes the flexion position, and exercises the balance board with both legs first and then one leg, opens the eyes first and then closes the eyes. Squat practice: squat on both legs first and then one leg (knee flexion around $40^{\circ}$ ), with throw the ball by hand to distract. Step flexibility exercise: balance training adopts forward step, backward step, side-by-side step and cross step.

This study mainly collected measurement results before balance training ( 1 month before surgery), after balance training (1 day before surgery), 6 weeks and 1 year after surgery. Data collection were performed in outpatient and inpatient wards equipped with special clinical examination rooms. Neither the sports medicine doctor who supervised the balance training nor the orthopedic surgeon who performed the surgery known the detailed basic data of the patients. All participants were told not to share the specific distribution of the study.

Early functional milestones, ROM were the primary measure outcomes. The main indicator for evaluating attain early functional milestones was the postoperative time of discontinued all walking aids; other functional milestones include discontinued walker/crutches, discontinued all narcotics, climb stairs, perform activities of daily living (ADL) independently, walk 0.5 mile. ROM refers to the arc of motion or 
rotation angle when the knee joint is in motion. The joint mobility is divided into active and passive joint mobility. The former is generated by the active contraction of the muscles, and the latter is generated by the external force. Here we mainly measured the active joint mobility of the knee joint. Early functional milestones was mainly obtained through telephone follow-up, and ROM requires the patient to go to the hospital to be measured by a doctor.

WOMAC score, KSS, KOOS score were the secondary measure outcome. Three scores were obtained through preoperative and postoperative questionnaires and telephone follow-up. KSS mainly includes pain, stability, range of activities, function and other items. WOMAC score scale evaluates the severity and treatment effect of arthritis through three major aspects of pain, stiffness, and joint function based on patient-related symptoms and signs. The scale is mostly used for the evaluation of OA, which can effectively reflect the status of patients before and after treatment, and has a high reliability for the evaluation of OA. KOOS score is a questionnaire for the evaluation of the treatment effect of knee injury and osteoarthropathy based on patient self-assessment management. This self-assessment method can reduce the observer error in the assessment. The scoring system is suitable for the evaluation of shortterm and long-term treatment effects after knee injury. Because of its reliability and effectiveness, the scoring tool is known as the most applicable health evaluation system in clinical practice and research related to the knee joint. For WOMAC score, we stipulate that the higher the score, the more serious the illness, and the lower the score, the lighter the illness; KSS score is normalized to a range of 0 to 100 with 85-100 points being excellent, 70-84 being good, $60-69$ being medium and less than 60 being bad; conversely, a higher KOOS Score indicates better knee indicators.

\section{Statistical method}

The analysis and production of data and charts were processed using IBM SPSS Statistics 16.0 statistical software (Statistical Package for the Social Sciences, Chicago, IL, USA). The measurement data that obey or approximately obey the normal distribution adopt the method of mean \pm standard deviation (mean \pm SD). The comparison of measurement data between the two groups used independent sample T-test. The categorical variable data of each group used Chi-square test or Fisher's exact test. The test level value of a was taken as 0.05 on both sides, $P<0.05$ means the difference was statistically significant.

\section{Results}

According to the inclusion and exclusion criteria, a total of 100 patients were included in this study. In the balance training group, there were 11 males and 39 females, aged 61-79 years, with an average age of (68.0 \pm 5.86$)$ years. In the control group, there were 15 males and 35 females, aged 58-83 years, with an average age of $(71.13 \pm 7.65)$ years. There was no statistically significant difference in gender, age, weight, height, BMI, ASA score, surgical side, duration of illness, intraoperative blood loss, operative time, length of hospital stay, follow-up time and complications among the two groups of patients $(P>0.05)$. 
The detailed preoperative data of the patients in the training group and the control group were shown in Table 1.

During the follow-up, we excluded patients who were not followed up before the operation ( 2 in the training group and 2 in the control group). 96 surgical patients were re-incorporated and measured the index. 2 patients were lost to follow-up within 6 weeks, and 3 within 3 months. 3 patients in the training group withdrew from the experimental plan due to CAOD, appendicitis, and ARF during the follow-up period. Control group withdrew 2 patients due to CAOD and cerebral hemorrhage. The number of patients with 3 months as the primary endpoint was 86 .

From Table 2, it can be concluded that the time to discontinued all narcotics $(P=0.045)$ and perform ADLs independently $(P=0.037)$ of the balance training group were earlier than those of the control group. No significant difference in postoperative ROM between the two groups after 6 weeks and 52 weeks. (Table 3)

About 1 month after balance training, no significant improvement in pain, stiffness and function compared with before balance training (A vs. B), however, after 6 weeks of surgery, pain $(P=0.048)$, stiffness $(P=0.034)$ and function $(P=0.026)$ improved significantly compared to before balance training (A vs. C). Compared with after balance training, the pain $(P=0.039)$ and stiffness $(P=0.040)$ and function $(P=0.031)$ improved in the 6 weeks after the operation. In the control group, the pain $(P=$ $0.044)$, stiffness $(P=0.041)$, and function $(P=0.032)$ of the 6 weeks after surgery were improved compared to before surgery (B vs. C). No statistically significant difference between 6 weeks and 52 weeks after operation. (Table 4)

In terms of KSS, no significant difference before and after balance training; 6 weeks after operation, the difference were obvious compared to before training, and no significant difference compared to after balance training. Similar to balance training, a significant improvement in KSS function after surgery compared to before surgery. (Table 4)

The aspects of KOOS score did not improve significantly after balance training. After surgery, the differences between training group and control group were statistically significant compared to those before surgery. (Table 4)

The comparison between the two groups at the end of 52 weeks after operation can be concluded that there is no significant difference between the two groups in terms of early functional milestones, ROM, WOMAC score, KSS, KOOS score, complications, etc. At 6 weeks after surgery, there were a significant difference in pain $(P=0.048)$, function $(P=0.017)$, and QOL $(P=0.028)$. (Table 5$)$

We compared the complication events of the two groups within 52 weeks and found no significant difference between the balance training group and the control group. (Table 6)

\section{Discussion}


The traditional view is that functional exercise during the perioperative period is to accelerate the recovery of patients. ${ }^{[1,2]}$ A study reported that about $20 \%$ of patients did not improve pain after TKA, and even had a tendency to aggravate after surgery, so that they did not fully restore body function. With this in mind, it will be necessary to implement a rehabilitation plan for patients who plan to undergo surgery. ${ }^{[25-27]}$ The study we conducted this time was to verify the effectiveness of rehabilitation therapy based on preoperative balance training as part of the treatment.

Jogi deemed that the addition of balance training to a typical rehabilitation program has a greater improvement in balance and functional activity than simple typical exercises. ${ }^{[28]}$ Liao deemed that additional balance training can significantly promote the functional recovery and activity of patients with knee OA after TKA. ${ }^{[29]}$ Liao also considered that postoperative rehabilitation training improves the balance, mobility and functional outcomes of patients with $O A .{ }^{\left[{ }^{[0]}\right.}$ Various evidence indicates that postoperative balance training has a positive effect on rehabilitation after TKA.

We were more interested in whether preoperative balance training has a positive significance for rehabilitation after TKA. Bitterli had conducted research on sensorimotor training after surgery, and concluded that sensory-motor training did not produce any useful effect on patients after surgery. ${ }^{[20]}$ Villadsen concluded that under the supervision of 3 months after surgery, the hip or knee joint for 8 weeks of neuromuscular exercise did not bring additional benefits, however, the training group had significant short-term benefits in terms of ADL and pain. ${ }^{[31]}$ Gstoettner also believed that preoperative proprioception training for TKA patients can improve standing balance, however, there was no difference in clinical effect between the two groups of patients. ${ }^{[21]}$ We assume that preoperative balance training has some positive effects on the recovery of patients after TKA at 6 weeks, which helps shorten the recovery time and optimize the postoperative state of the patients.

The surgeon will inevitably remove the tissue structures that maintain the proprioception of the knee during the total knee replacement surgery. These tissue structures included the cruciate ligament, articular cartilage and menisci. We purposefully chosed posterior cruciate ligament (PCL) remainned prosthesis in this study because the use of this prosthesis can effectively avoided the removal of PCL and reduced the loss of proprioceptors. In addition, because many other proprioceptors are located outside the capsule of the tissue around the joint, ${ }^{[32-34]}$ we kept this part of the tissue as much as possible during the operation to ensure the smooth progress of the study.

The balance training group stopped using analgesic drugs earlier, indicating that the preoperative balance training can effectively relieve the postoperative pain, the earlier ADL in the balance training group may be related to the earlier relief of pain.

In order to exclude the differences between the groups, we analyzed the detailed scores of the balanced group and the control group at four time points. We took 6 weeks and 52 weeks after surgery as the endpoint, the purpose is to compare the recovery of the two groups after surgery. 
It can be seen from Table 4 that there were no statistically significant difference between the two groups in terms of WOMAC score, KSS, KOOS score before and after balance training (A vs. B). We assumed that the effect of balance training and the progress of knee OA cancel each other out. Compared with those before balance training, the two groups showed significant improvements in aspects of pain, function, symptoms, QOL and stiffness at 6 weeks after TKA (A vs. C), which proved that TKA has clear benefits in the treatment of knee OA. Compared with the end of balance training (B vs. C), the patient continued to improved in pain, and QOL at 6 weeks after surgery, indicating that total knee arthroplasty further strengthened the patient's postoperative rehabilitation. No statistically significant difference between the 6 weeks and the 52 weeks after operation (C vs. D). It shows that the patients' indexes have recovered and improved after 6 weeks.

Because table 4 did not perform well in other differences between the balance training group and control group, we added table 5 to make a partial comparison of the two groups. It can be drawn from Table 5 that no statistically significant difference in outcome parameters such as KSS, KOOS, and WOMAC score between the balance training group and the control group at 52 weeks after surgery. It's shows that in the mid-term with the end of 52 weeks, no difference between the two groups, however, at 6 weeks after surgery, the balance training group showed the advantage of early rehabilitation in pain, ADL function, and QOL. These outcomes were similar to the experimental conclusion of Villadsen. ${ }^{[30]}$

Two groups of patients were operated by two experienced professional surgeons, and all patients underwent postoperative rehabilitation treatment under the same conditions. Postoperative complications were similar in both groups, indicating that balance training will not reduce the probability of postoperative complications.

This is a randomized controlled study. All stages of the study follow strict standards, including inclusion and exclusion criteria, blinding experimental participants, and excluding inappropriate persons during follow-up, with the aim of improving the rigour of the study. In the study, we observed that during postoperative rehabilitation, patients who have received balance training will always involuntarily perform balance training, which may be closely related to the habitual behaviors developed by patients. Since we cannot exclude correlations, this may affect the accuracy of the study, however, we try to avoid this effect as much as possible. Whether the patients participating in the study can follow the doctor's instructions for effective and rigorous training at home is an important factor in determining the reliability of the study. The uncontrollability of participants' balanced training makes this study potentially risky.

\section{Conclusions}

It can be seen from this study that performing TKA on patients with OA can improve many symptoms of the patient and make the patient adapt to life better. For the preoperative balance training, with the main endpoint of 1 year after surgery, the one-month balance training before surgery did not show obvious advantages, however, preoperative balance training was not completely ineffective for patients, from the 
outcome of 6 weeks after surgery, it can be found that balance training has an early effect on pain relief, improving function and QOL.

\section{Abbreviations}

TKA: Total knee arthroplasty; RCT: Randomized controlled trial; ROM: range of motion; KSS: Keen society score; BMI: Body mass index; KOOS: Knee disability and osteoarthritis outcome; ADL: Activities of daily living; ASA: American Society of Anesthesiologists; CVA: Cerebral vascular accident; LOS: Length of hospital stay; CAOD: Coronary artery obstructive disease; DVT: Deep vein thrombosis.

\section{Declarations}

\section{Acknowledgements}

None.

\section{Authors' contributions}

WC, SF, and XYC designed the research ideas, analyzed the data. WC wrote out the original manuscript. JNS and ZHH took part in the design of the study. The co-authors read and authorized the final manuscript for publication. The author(s) read and approved the final manuscript.

\section{Funding}

No financial support.

\section{Availability of data and materials}

All data were contained in the text and charts of published articles.

\section{Ethics approval and consent to participate}

The study has been approved by the local ethics committee.

\section{Consent for publication}

The co-authors agreed on the final manuscript.

\section{Competing interests}

The co-authors claimed that there was no competition between them.

Reference 
1. Brandes $M$, Ringling $M$, Winter $C$, et al. Changes in physical activity and health-related quality of life during the first year after total knee arthroplasty. Arthritis Care and Research. 2011; 63:328-334.

2. Meier W, Mizner R, Marcus R, et al. Total knee arthroplasty: Muscle impairments, functional limitations, and recommended rehabilitation approaches. Journal of Orthopaedic and Sports Physical Therapy. 2008; 38:246-256.

3. Vissers M, Bussmann J, de Groot I, et al. Physical functioning four years after total hip and knee arthroplasty. Gait \& Posture. 2013; 38:310-315. (2012) 9th Annual Report National Joint Registry for England and Wales. NJR Centre, Northgate Solutions, Hemel Hempstead.

4. Kahlenberg CA, Nwachukwu BU, McLawhorn AS. Patient satisfaction after total knee replacement: a systematic review. HSS J. 2018; 14(2):192-201.

5. Beswick AD, Wylde V, Gooberman-Hill R, et al. What proportion of patients report long-term pain after total hip or knee replacement for osteoarthritis? A systematic review of prospective studies in unselected patients. BMJ Open. 2012; 2(1):e000435.

6. Lee A, Park J, Lee S. Gait analysis of elderly women after total knee arthroplasty. J Phys Ther Sci. 2015; 27(3):591-595.

7. Mauer AC, Draganich LF, Pandya N. Bilateral total knee arthroplasty increases the propensity to trip on an obstacle. Clin Orthop Relat Res. 2005; 433:160-165.

8. Gage WH, Frank JS, Prentice SD, et al. Postural responses following a rotational support surface perturbation, following knee joint replacement: frontal plane rotations. Gait \& Posture. 2008; 27:286293.

9. Bruun-Olsen V, Heiberg KE, Mengshoel AM. Continuous passive motion as an adjunct to active exercises in early rehabilitation following total knee arthroplasty-a randomized controlled trial. Disabil Rehabil. 2009; 31:277-283.

10. Heiberg KE, Bruun-Olsen V, Mengshoel AM. Pain and recovery of physical functioning nine months after total knee arthroplasty. J Rehabil Med. 2010; 42:614-619.

11. Desmeules F, Dionne CE, Belzile ÉL. Determinants of pain, functional limitations and health-related quality of life six months after total knee arthroplasty: results from a prospective cohort study. Sports Medicine, Arthroscopy, Rehabilitation, Therapy \& Technology. 2013; 5(1):1-11.

12. Moutzouri M, Gleeson N, Billis E. The effect of total knee arthroplasty on patients' balance and incidence of falls: a systematic review. Knee Surg Sports Traumatol Arthrosc. 2017; 25(11):34393451 .

13. Moutzouri M, Gleeson N, Coutts F. Early self-managed focal sensorimotor rehabilitative training enhances functional mobility and sensorimotor function in patients following total knee replacement: a controlled clinical trial. Clin Rehabil. 2018; 32(7):888-898.

14. Lingard EA, Mitchell SY, Francis RM. The prevalence of osteoporosis in patients with severe hip and knee osteoarthritis awaiting joint arthroplasty. Age and Ageing. 2009; 39(2):234 239.

15. Duncan PW, Chandler J, Studenski S. How do physiological components of balance affect mobility in elderly men? Arch Phys Med Rehabil. 1993; 74:1343-1349. Page P. Sensorimotor training: a 'global' 
approach for balance training. J Bodywork Move Therap. 2006; 10(1):77-84.

16. Domínguez-Navarro F, Igual-Camacho C, SilvestreMuñoz A. Effects of balance and proprioceptive training on total hip and knee replacement rehabilitation: a systematic review and meta-analysis. Gait \& Posture. 2018; 62:68-74.

17. Moutzouri M, Gleeson N, Billis E. What is the effect of sensori-motor training on functional outcome and balance performance of patients' undergoing TKR? a systematic review. Physiotherapy. 2016; 102(2):136-144.

18. Bitterli R, Sieben JM, Hartmann M. Pre-surgical Sensorimotor Training for Patients Undergoing Total Hip Replacement: A Randomised Controlled Trial. Int J Sports Med. 2011; 32(9):725-32.

19. Gstoettner, M., Raschner, C. \& Dirnberger, E. Preoperative Proprioceptive Training in Patients With Total Knee Arthroplasty. Knee. 18(4), 265-70 (2011).

20. Kellgren JH. Lawrence JS. Radiological assessment of osteo-arthrosis. Ann Rheum Dis. 1957; 16(4):494-502.

21. Harriss DJ, Atkinson G. International Journal of Sports Medicine-Ethical Standards in Sport and Exercise Science Research. Int J Sports Med. 2009; 30:701-702.

22. Brotzman SB, Manske RC. Clinical orthopaedic rehabilitation: an evidence-based approach-expert consult. Elsevier Health Sciences. 2011.

23. Nilsdotter A-K, Toksvig-Larsen S, Roos EM. A 5 Year Prospective Study of Patient-Relevant Outcomes After Total Knee Replacement. Osteoarthritis Cartilage. 2009; 17(5):601 606.

24. Beswick AD, Wylde V, Gooberman-Hill R, et al. What proportion of patients report long-term pain after total hip or knee replacement for osteoarthritis? A systematic review of prospective studies in unselected patients. BMJ Open. 2012; 2(1):e000435.

25. Vissers MM, Bussmann JB, Verhaar JA, et al. Recovery of physical functioning after total hip arthroplasty: systematic review and meta-analysis of the literature. Phys Ther. 2011; 91(5): 615-29.

26. Jogi P, Overend TJ, Spaulding SJ. Effectiveness of Balance Exercises in the Acute Post-Operative Phase Following Total Hip and Knee Arthroplasty: A Randomized Clinical Trial. SAGE Open Med. 2015; 3:2050312115570769.

27. Liao CD, Liou TH, Huang YY. Effects of Balance Training on Functional Outcome After Total Knee Replacement in Patients With Knee Osteoarthritis: A Randomized Controlled Trial. Clin Rehabil. 2013; 27(8):697-709.

28. Liao CD, Lin LF, Huang YC. Functional Outcomes of Outpatient Balance Training Following Total Knee Replacement in Patients With Knee Osteoarthritis: A Randomized Controlled Trial. Clin Rehabil. 2015; 29(9):855-67.

29. Villadsen A, Overgaard S, Holsgaard-Larsen A. Postoperative Effects of Neuromuscular Exercise Prior to Hip or Knee Arthroplasty: A Randomised Controlled Trial. Ann Rheum Dis. 2014; 73(6):1130-1137.

30. Goodwin GM, McCloskey DI, Matthews PB. The persistence of appreciable kinesthesia after paralysing joint afferents but preserving muscle afferents. Brain Res. 1972; 37(2):326 329. 
31. Merton PA. Human position sense and sense of effort. Symp Soc Exp Biol. 1964; 18:387-400.

32. Grigg P, Finerman GA, Riley LH. Joint-position sense after total hip replacement. J Bone Joint Surg Am. 1973; 55(5):1016-1025.

\section{Tables}

Table 1 The detailed preoperative data of the patients in the balance training group and the control group.

\begin{tabular}{|c|c|c|c|}
\hline & Banlance Training Group $(n=42)$ & $\begin{array}{l}\text { Control Group } \\
(n=44)\end{array}$ & $P$ Value \\
\hline Gender (male/female) & $11 / 31$ & $14 / 30$ & N.S. ${ }^{+}$ \\
\hline Age (years) & $66.0 \pm 5.86$ & $67.13 \pm 6.65$ & N.S.* \\
\hline$<61$ & 8 & 10 & \\
\hline $61-70$ & 20 & 22 & \\
\hline$>71$ & 14 & 12 & \\
\hline Weight (kg) & $62.14 \pm 7.0$ & $61.0 \pm 6.14$ & N.S. ${ }^{*}$ \\
\hline Height (m) & $1.58 \pm 0.08$ & $1.56 \pm 0.06$ & N.S.* \\
\hline BMI (kg/m2) & $24.89 \pm 2.86$ & $25.07 \pm 1.41$ & N.S.* \\
\hline ASA class & $2.5 \pm 0.50$ & $2.5 \pm 0.50$ & N.S. ${ }^{+}$ \\
\hline Surgical side (left/right) & $20 / 22$ & $21 / 23$ & N.S. ${ }^{\dagger}$ \\
\hline \multicolumn{4}{|l|}{ Comorbidity (\%) } \\
\hline Hypertension & 35.71 & 42.86 & \\
\hline CVA & 7.14 & 14.28 & \\
\hline Diabetes & 21.48 & 28.57 & \\
\hline CAOD & 7.14 & 28.57 & \\
\hline Intraoperative blood loss (ml) & $133.36 \pm 35.36$ & $121.68 \pm 34.13$ & N.S.* \\
\hline Operative time (min) & $104.93 \pm 29.77$ & $103.21 \pm 42.93$ & N.S. ${ }^{*}$ \\
\hline LOS (day) & $10.83 \pm 0.58$ & $11.24 \pm 0.94$ & N.S.* \\
\hline Follow-up time (week) & $54.50 \pm 2.88$ & $53.78 \pm 5.10$ & N.S.* \\
\hline
\end{tabular}


Abbreviations: N.S., no significance; BMI, body mass index; ASA, American Society of Anesthesiologists; CVA, cerebral vascular accident; LOS, length of hospital stay; CAOD, coronary artery obstructive disease. ${ }^{*} \mathrm{P}$ value means that student's $t$ test were used; ${ }^{\dagger} \mathrm{P}$ value indicates that the Chi squared test were used.

Table 2 Comparison of two groups of Days to Attain Early Functional Milestones.

\begin{tabular}{|llll|}
\hline Milestone & \multicolumn{2}{l}{ CG } & $P$ value \\
& TG & & \\
\hline Discontinued walker/crutches & $14.6 \pm 2.4$ & $15.0 \pm 1.8$ & N.S. $^{*}$ \\
\hline Discontinued all walking aids & $25.2 \pm 5.6$ & $28 \pm 6.0$ & N.S. $^{*}$ \\
\hline Discontinued all narcotics & $16.1 \pm 4.1$ & $25 \pm 5.4$ & $0.045^{*}$ \\
\hline Climb stairs & $14.8 \pm 4.7$ & $16.2 \pm 5.1$ & N.S. $^{*}$ \\
\hline Perform ADLs independently & $21.2 \pm 5.8$ & $30.5 \pm 6.4$ & $0.037^{*}$ \\
\hline Walk 0.5 mile & $29.3 \pm 6.4$ & $28.7 \pm 5.8$ & N.S. $^{*}$ \\
\hline
\end{tabular}

Abbreviations: N.S., no significance

*P value means that student's $t$ test were used.

Table 3 Comparison of ROM at 6 and 52 weeks after surgery between the two groups.

\begin{tabular}{|c|c|c|c|c|c|c|}
\hline & \multicolumn{2}{|c|}{6 weeks after TKA } & \multicolumn{2}{|c|}{52 weeks after TKA } & \multirow{2}{*}{$\begin{array}{l}\text { Differences } \\
\text { between CG and } \\
\text { TG at } 6 \text { weeks } \\
(P)\end{array}$} & \multirow{2}{*}{$\begin{array}{l}\text { Differences } \\
\text { between CG and } \\
\text { TG at } 52 \text { weeks } \\
(P)\end{array}$} \\
\hline & TG & CG & TG & CG & & \\
\hline ROM & $90.6 \pm 8.6$ & $92.8 \pm 10.3$ & $113.2 \pm 9.7$ & $109.8 \pm 11.5$ & 0.785 & 0.648 \\
\hline
\end{tabular}

*P value means that student's $t$ test were used.

TTable 4 Data of the balance training group and the control group at different time-point. 


\begin{tabular}{|c|c|c|c|c|c|c|c|c|c|}
\hline & \multirow[t]{2}{*}{ Outcomes } & \multirow{2}{*}{$\begin{array}{l}\text { Before } \\
\text { training } \\
(\mathrm{A})^{\star}\end{array}$} & \multirow{2}{*}{$\begin{array}{l}\text { One day } \\
\text { before } \\
\text { surgery } \\
(B)^{*}\end{array}$} & \multirow{2}{*}{$\begin{array}{l}6 \text { weeks } \\
\text { after } \\
\text { surgery } \\
(\mathrm{C})^{*}\end{array}$} & \multirow{2}{*}{$\begin{array}{l}52 \\
\text { weeks } \\
\text { after } \\
\text { surgery } \\
(D)^{\star}\end{array}$} & \multicolumn{4}{|c|}{$\begin{array}{l}\text { Statistical differences of } P \\
\text { values }^{*}\end{array}$} \\
\hline & & & & & & $\begin{array}{l}\text { Avs. } \\
\text { B }\end{array}$ & $\begin{array}{l}\text { Avs. } \\
\text { C }\end{array}$ & B vs. & $\begin{array}{l}\text { C vs. } \\
\text { D }\end{array}$ \\
\hline & $\begin{array}{l}\text { WOMAC } \\
\text { Score }\end{array}$ & & & & & & & & \\
\hline \multirow[t]{3}{*}{ TG } & Pain & $\begin{array}{l}30.8 \pm \\
6.1\end{array}$ & $\begin{array}{l}29.1 \pm \\
5.2\end{array}$ & $7.1 \pm 4.3$ & $6.6 \pm 2.1$ & 0.367 & 0.048 & 0.039 & 0.653 \\
\hline & Stiffness & $\begin{array}{l}7.2 \pm \\
2.3\end{array}$ & $6.9 \pm 2.7$ & $1.6 \pm 1.0$ & $1.5 \pm 1.4$ & 0.621 & 0.034 & 0.040 & 0.751 \\
\hline & Function & $\begin{array}{l}74.2 \pm \\
11.6\end{array}$ & $\begin{array}{l}72.4 \pm \\
13.4\end{array}$ & $\begin{array}{l}28.4 \pm \\
7.4\end{array}$ & $\begin{array}{l}26.2 \pm \\
6.3\end{array}$ & 0.275 & 0.026 & 0.031 & 0.218 \\
\hline \multirow[t]{4}{*}{ CG } & Pain & $\begin{array}{l}31.2 \pm \\
5.4\end{array}$ & $\begin{array}{l}30.9 \pm \\
6.2\end{array}$ & $\begin{array}{l}14.6 \pm \\
4.7\end{array}$ & $6.9 \pm 1.9$ & 0.745 & 0.037 & 0.044 & 0.489 \\
\hline & Stiffness & $\begin{array}{l}7.6 \pm \\
1.8\end{array}$ & $6.8 \pm 2.1$ & $1.9 \pm 1.4$ & $1.6 \pm 1.2$ & 0.558 & 0.038 & 0.041 & 0.526 \\
\hline & Function & $\begin{array}{l}73.8 \pm \\
13.3\end{array}$ & $\begin{array}{l}72.1 \pm \\
12.5\end{array}$ & $\begin{array}{l}35.7 \pm \\
13.5\end{array}$ & $\begin{array}{l}28.4 \pm \\
12.3\end{array}$ & 0.446 & 0.047 & 0.032 & 0.634 \\
\hline & $\begin{array}{l}\text { Keen } \\
\text { Society } \\
\text { Score }\end{array}$ & & & & & & & & \\
\hline \multirow[t]{2}{*}{ TG } & Function & $\begin{array}{l}26.9 \pm \\
11.4\end{array}$ & $\begin{array}{l}29.3 \pm \\
12.4\end{array}$ & $\begin{array}{l}66.9 \pm \\
19.8\end{array}$ & $\begin{array}{l}69.6 \pm \\
17.3\end{array}$ & 0.542 & 0.026 & 0.036 & 0.442 \\
\hline & Total & $\begin{array}{l}58.3 \pm \\
17.4\end{array}$ & $\begin{array}{l}57.6 \pm \\
16.8\end{array}$ & $\begin{array}{l}86.3 \pm \\
26.4\end{array}$ & $\begin{array}{l}90.9 \pm \\
28.2\end{array}$ & 0.627 & 0.039 & 0.044 & 0.651 \\
\hline \multirow[t]{3}{*}{ CG } & Function & $\begin{array}{l}27.7 \pm \\
12.1\end{array}$ & $\begin{array}{l}31.9 \pm \\
13.4\end{array}$ & $\begin{array}{l}52.2 \pm \\
17.6\end{array}$ & $\begin{array}{l}66.5 \pm \\
18.4\end{array}$ & 0.391 & 0.049 & 0.041 & 0.749 \\
\hline & Total & $\begin{array}{l}57.9 \pm \\
17.9\end{array}$ & $\begin{array}{l}58.6 \pm \\
18.7\end{array}$ & $\begin{array}{l}85.4 \pm \\
23.6\end{array}$ & $\begin{array}{l}91.6 \\
\pm 25.8\end{array}$ & 0.612 & 0.037 & 0.034 & 0.538 \\
\hline & $\begin{array}{l}\text { KOOS } \\
\text { Score }\end{array}$ & & & & & & & & \\
\hline \multirow[t]{4}{*}{ TG } & $\begin{array}{l}A D L \\
\text { function }\end{array}$ & $\begin{array}{l}28.4 \pm \\
6.5\end{array}$ & $\begin{array}{l}27.9 \pm \\
7.5\end{array}$ & $\begin{array}{l}56.4 \pm \\
10.4\end{array}$ & $\begin{array}{l}59.3 \pm \\
12.5\end{array}$ & 0.578 & 0.035 & 0.046 & 0.520 \\
\hline & Pain & $\begin{array}{l}16.5 \pm \\
5.7\end{array}$ & $\begin{array}{l}14.8 \pm \\
8.3\end{array}$ & $\begin{array}{l}29.2 \pm \\
9.5\end{array}$ & $\begin{array}{l}31.5 \pm \\
8.7\end{array}$ & 0.253 & 0.048 & 0.037 & 0.631 \\
\hline & symptoms & $\begin{array}{l}13.7 \pm \\
6.3\end{array}$ & $\begin{array}{l}12.5 \pm \\
6.2\end{array}$ & $\begin{array}{l}22.3 \pm \\
7.9\end{array}$ & $\begin{array}{l}23.6 \pm \\
8.4\end{array}$ & 0.324 & 0.031 & 0.042 & 0.714 \\
\hline & $\begin{array}{l}\text { Sport and } \\
\text { recreation }\end{array}$ & $\begin{array}{l}10.6 \pm \\
4.8\end{array}$ & $9.7 \pm 5.7$ & $\begin{array}{l}14.6 \pm \\
5.8\end{array}$ & $\begin{array}{l}15.5 \pm \\
6.6\end{array}$ & 0.189 & 0.028 & 0.031 & 0.129 \\
\hline
\end{tabular}




\begin{tabular}{|c|c|c|c|c|c|c|c|c|c|}
\hline & $\begin{array}{l}\text { Quality of } \\
\text { life }\end{array}$ & $\begin{array}{l}8.2 \pm \\
2.9\end{array}$ & $7.9 \pm 4.3$ & $\begin{array}{l}15.1 \pm \\
6.2\end{array}$ & $\begin{array}{l}15.9 \pm \\
5.4\end{array}$ & 0.537 & 0.03 & 0.045 & 0.257 \\
\hline CG & $\begin{array}{l}\mathrm{ADL} \\
\text { function }\end{array}$ & $\begin{array}{l}31.8 \pm \\
7.4\end{array}$ & $\begin{array}{l}29.5 \pm \\
8.9\end{array}$ & $\begin{array}{l}43.5 \pm \\
12.1\end{array}$ & $\begin{array}{l}56.2 \pm \\
13.1\end{array}$ & 0.257 & 0.049 & 0.036 & 0.361 \\
\hline & Pain & $\begin{array}{l}17.4 \pm \\
8.4\end{array}$ & $\begin{array}{l}18.6 \pm \\
10.8\end{array}$ & $\begin{array}{l}21.1 \pm \\
8.6\end{array}$ & $\begin{array}{l}30.7 \pm \\
7.4\end{array}$ & 0.367 & 0.038 & 0.037 & 0.885 \\
\hline & symptoms & $\begin{array}{l}14.2 \pm \\
7.6\end{array}$ & $\begin{array}{l}13.2 \pm \\
5.6\end{array}$ & $\begin{array}{l}21.9 \pm \\
7.9\end{array}$ & $\begin{array}{l}22.9 \pm \\
7.9\end{array}$ & 0.292 & 0.046 & 0.029 & 0.741 \\
\hline & $\begin{array}{l}\text { Sport and } \\
\text { recreation }\end{array}$ & $\begin{array}{l}9.5 \pm \\
3.6\end{array}$ & $8.3 \pm 3.9$ & $\begin{array}{l}13.4 \pm \\
6.4\end{array}$ & $\begin{array}{l}15.1 \pm \\
5.3\end{array}$ & 0.873 & 0.044 & 0.034 & 0.328 \\
\hline & $\begin{array}{l}\text { Quality of } \\
\text { life }\end{array}$ & $\begin{array}{l}8.6 \pm \\
3.1\end{array}$ & $7.6 \pm 5.2$ & $\begin{array}{l}11.3 \pm \\
5.8\end{array}$ & $\begin{array}{l}15.8 \pm \\
6.7\end{array}$ & 0.425 & 0.038 & 0.045 & 0.632 \\
\hline
\end{tabular}

*P value means that student's $t$ test were used.

Table 5 Comparison of three scores between the balance training group and the control group at 6 and 52 weeks after surgery. 


\begin{tabular}{|c|c|c|c|c|c|c|}
\hline \multirow[t]{2}{*}{ Outcomes } & \multicolumn{2}{|c|}{6 weeks after TKA ${ }^{*}$} & \multicolumn{2}{|c|}{52 weeks after TKA } & \multirow{2}{*}{$\begin{array}{l}\text { Differences } \\
\text { between CG } \\
\text { and TG at } 6 \\
\text { weeks }(P)^{*}\end{array}$} & \multirow{2}{*}{$\begin{array}{l}\text { Differences } \\
\text { between CG } \\
\text { and TG at } 52 \\
\text { weeks }\left(P^{*}\right.\end{array}$} \\
\hline & TG & CG & TG & CG & & \\
\hline \multicolumn{7}{|l|}{$\begin{array}{l}\text { WOMAC } \\
\text { Score }\end{array}$} \\
\hline Pain & $7.1 \pm 4.3$ & $14.6 \pm 4.7$ & $6.6 \pm 2.1$ & $6.9 \pm 1.9$ & 0.048 & 0.624 \\
\hline Stiffness & $1.6 \pm 1.0$ & $1.9 \pm 1.4$ & $1.5 \pm 1.4$ & $1.6 \pm 1.2$ & 0.751 & 0.582 \\
\hline Function & $28.4 \pm 7.4$ & $35.7 \pm 13.5$ & $26.2 \pm 6.3$ & $28.4 \pm 12.3$ & 0.039 & 0.512 \\
\hline \multicolumn{7}{|l|}{$\begin{array}{l}\text { Keen } \\
\text { Society } \\
\text { Score }\end{array}$} \\
\hline Function & $66.9 \pm 19.8$ & $52.2 \pm 17.6$ & $69.6 \pm 17.3$ & $66.5 \pm 18.4$ & 0.017 & 0.825 \\
\hline Total & $86.3 \pm 26.4$ & $85.4 \pm 23.6$ & $90.9 \pm 28.2$ & $\begin{array}{l}91.6 \\
\pm 25.8\end{array}$ & 0.287 & 0.341 \\
\hline \multicolumn{7}{|l|}{$\begin{array}{l}\text { KOOS } \\
\text { Score }\end{array}$} \\
\hline $\begin{array}{l}A D L \\
\text { function }\end{array}$ & $56.4 \pm 10.4$ & $43.5 \pm 12.1$ & $59.3 \pm 12.5$ & $56.2 \pm 13.1$ & 0.027 & 0.821 \\
\hline Pain & $29.2 \pm 9.5$ & $21.1 \pm 8.6$ & $31.5 \pm 8.7$ & $30.7 \pm 7.4$ & 0.046 & 0.635 \\
\hline symptoms & $22.3 \pm 7.9$ & $21.9 \pm 7.9$ & $23.6 \pm 8.4$ & $22.9 \pm 7.9$ & 0.249 & 0.247 \\
\hline $\begin{array}{l}\text { Sport and } \\
\text { recreation }\end{array}$ & $14.6 \pm 5.8$ & $13.4 \pm 6.4$ & $15.5 \pm 6.6$ & $15.1 \pm 5.3$ & 0.482 & 0.318 \\
\hline $\begin{array}{l}\text { Quality of } \\
\text { life }\end{array}$ & $15.1 \pm 6.2$ & $11.3 \pm 5.8$ & $15.9 \pm 5.4$ & $15.8 \pm 6.7$ & 0.028 & 0.465 \\
\hline
\end{tabular}

*P value means that student's $t$ test were used.

Table 6 Comparison of postoperative complications with 52 weeks as the main endpoint of the two groups. 


\begin{tabular}{|c|c|c|c|}
\hline \multirow[t]{2}{*}{ Complications (n) } & \multirow[t]{2}{*}{ TG } & \multirow[t]{2}{*}{ CG } & Differences between CG and \\
\hline & & & TG at 52 weeks after TKA $(P)^{*}$ \\
\hline Cardiac complications & 0 & 1 & $>0.05$ \\
\hline Confusion & 0 & 0 & \\
\hline Stroke & 0 & 0 & \\
\hline Pneumonia & 1 & 0 & $>0.05$ \\
\hline Pulmonary embolism & 0 & 0 & \\
\hline Superficial infection & 1 & 0 & $>0.05$ \\
\hline Deep infection & 0 & 0 & \\
\hline Skin edge necrosis & 0 & 1 & $>0.05$ \\
\hline Deep vein thrombosis & 1 & 0 & $>0.05$ \\
\hline Nerve palsy & 0 & 0 & \\
\hline Death & 0 & 0 & \\
\hline
\end{tabular}

*P value means that student's $t$ test were used.

Figures 


\section{CONSORT 2010 Flow Diagram}

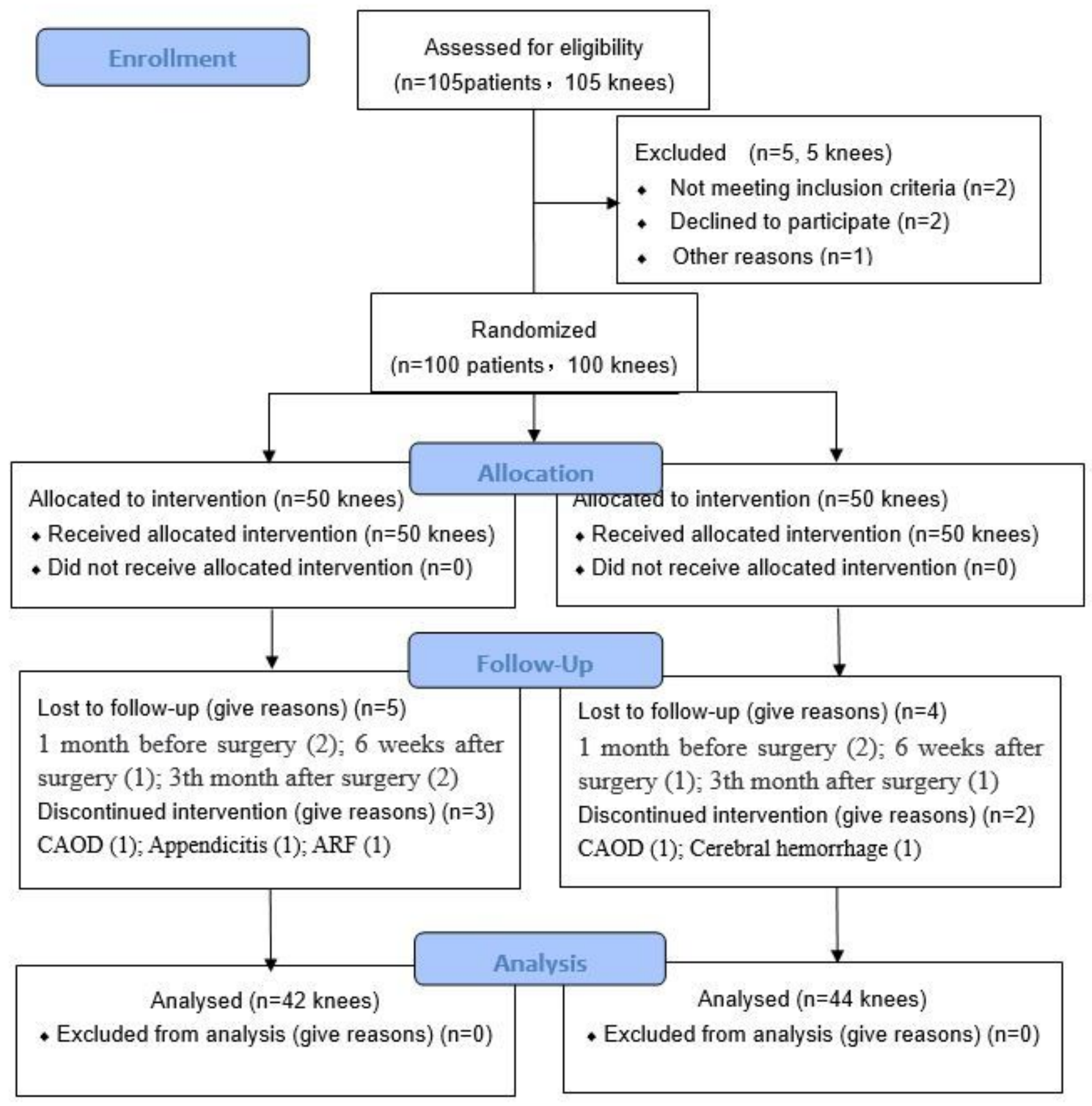

\section{Figure 1}

Flow diagram of patients participating in this study. 